\title{
Analysis of Combined Motor Current Signature and Vibration-Monitoring Techniques in the Study of Broken Bars in Three-Phase High-Performance Induction Motors
}

Ronaldo Siqueira da Gama, Caio César Jacob Silva, Carlos Eduardo Ferreira Nascimento, Alexandre Messias da Silva and Cesar da Costa* Control and Automation Engineering, IFSP-Federal Institute of Education, SP, 01109-010, Brazil

\begin{abstract}
Anomalies in operation of the motor modify harmonic content of motor supply current. Motor electrical current signature analysis (MCSA) is sensing an electrical signal containing current components. In this work, by introducing progressive failures to a healthy motor, we investigated the efficacy of combining motor current signature analysis with vibration-monitoring techniques for the detection of broken bars in the squirrel-cage rotors of three-phase high-efficiency induction motors, which are the new standard in Brazilian industry. Our results demonstrate that the combined approach improves reliability in the diagnosis of broken bars.
\end{abstract}

Keywords: Induction motor; Vibration; MCSA

\section{Introduction}

Induction motors are an important source of power for installed machinery, mainly due to their robustness, reliability, reduced operational cost, and ease of maintenance [1-5]. They consume about $85 \%$ of the power used in Brazilian industrial plants and for power of up to $500 \mathrm{hp}$, the most commonly used rotor is the squirrel-cage type [6,7]. The occurrence of broken bars in induction motors is one of the major causes of production process failure and interruption, accounting for approximately $10 \%$ of these occurrences [8-10]. This type of failure is more common in large motors that operate under heavy load cycles and are subject to large inertia, and because of their high cost, often do not have immediate substitutes. Therefore, they are considered to be critical machinery in the production process. Some defects originate in the manufacturing process and can remain hidden for some time before gradually developing into more apparent problems $[4,6]$.

In this context, maintenance systems become important as they directly influence the availability of plant equipment. These systems often rely on predictive maintenance techniques in which variables are monitored as reference parameters for subsequent analysis [1,9]. This has been a reliable approach for providing an indication of the condition of machinery. In fault monitoring systems, it is also important that detection occurs in the early stages of fault development when the associated damage can be more easily reversed and to allow more scope in corrective intervention schedules [11-13].

As such, there have been a rich and wide variety of investigations regarding the detection of motor failures, as well as studies that combine monitoring methods with diagnostic techniques, such as motor current signature analysis (MCSA) and vibration analysis. Antonino-Daviu et al. [14] developed a reliable indicator for detecting the severity of non-adjacent broken rotor bars in induction motors. Siddiqui et al. [6] used transformative techniques for detecting broken rotor bar faults in induction motors. Pires et al. [8] conducted motor square current signature analysis in the diagnosis of induction motor rotors. Wang et al. [15] also studied diagnostic techniques for broken rotor bars in induction motors. Historically, vibration-monitoring techniques have been used widely for diagnosing broken bars in induction motors, but, as reported by Naha et al. [5], in recent years current detection methods have become popular. In this work, we develop an analysis method that combines MCSA and vibration techniques for the detection of broken bars in three-phase high-performance induction motors.

\section{MCSA}

In this approach, detection is performed by an activation check of the frequencies of specific lateral bands around the fundamental frequency associated with this particular fault. The difference between the lateral range and the fundamental frequency depends on the slip of the motor and these differences are generally small. Therefore, adequate frequency resolution is an important criteria when evaluating the spectrum amplitudes of the side bands, without which the evaluated spectrum will not be sufficiently sensitive to detect faults.

The spectral analysis approach is based on the fact that whenever a motor experiences a change in its mechanical or electrical characteristics due to some anomaly, one of its frequency spectrum components will also be altered. This analysis tool is based on the Fourier theorem, which established that any periodic function in the time domain can be decomposed into a series of pure sine waves with distinct and multiple frequencies of the fundamental signal frequency called the harmonics, which constitute the signal frequency spectrum [16]. This principle can best be understood by the visualization shown in Figure 1 .

According to the authors, Boughrara et al. [2], faults are indicated not only by variations in the amplitudes of the spectral components but mainly their frequencies, by which the spectra indicate which part of the equipment is deteriorating. As explained by Naha et al. [5], the cage rotor bars form parallel paths joined at the ends by short rings. The stator poles divide the rotor bars into parallel circuits equal in number to the number of stator poles. So, a two-pole winding divides the rotor into two parallel circuits that continuously move around the rotor cage. Any broken bars in the rotor alter this current distribution, and the

*Corresponding author: Cesar da Costa, Control and Automation Engineering, IFSP-Federal Institute of Education, SP, 01109-010, Brazil, Tel: +5511976407234; E-mail: ccosta@ifsp.edu.br

Received June 07, 2017; Accepted August 29, 2017; Published September 08 2017

Citation: da Gama RS, Silva CCJ, Nascimento CEF, da Silva AM, da Costa C (2017) Analysis of Combined Motor Current Signature and Vibration-Monitoring Techniques in the Study of Broken Bars in Three-Phase High-Performance Induction Motors. J Electr Electron Syst 6: 235. doi: 10.4172/2332-0796.1000235

Copyright: (c) 2017 da Gama RS, et al. This is an open-access article distributed under the terms of the Creative Commons Attribution License, which permits unrestricted use, distribution, and reproduction in any medium, provided the original author and source are credited. 


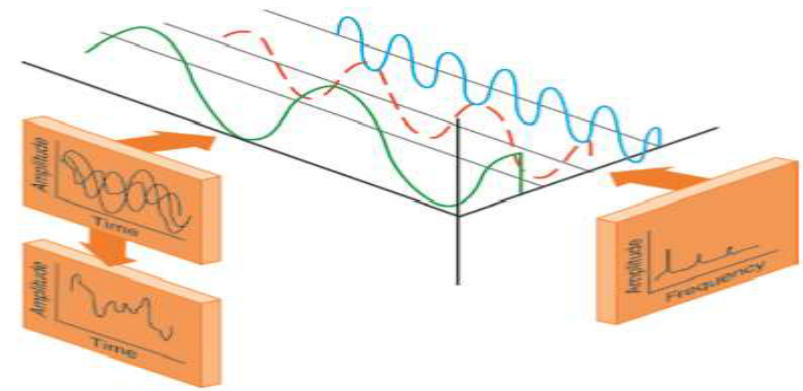

Figure 1: Signal in the time (left) and frequency (right) domains with its spectral components.

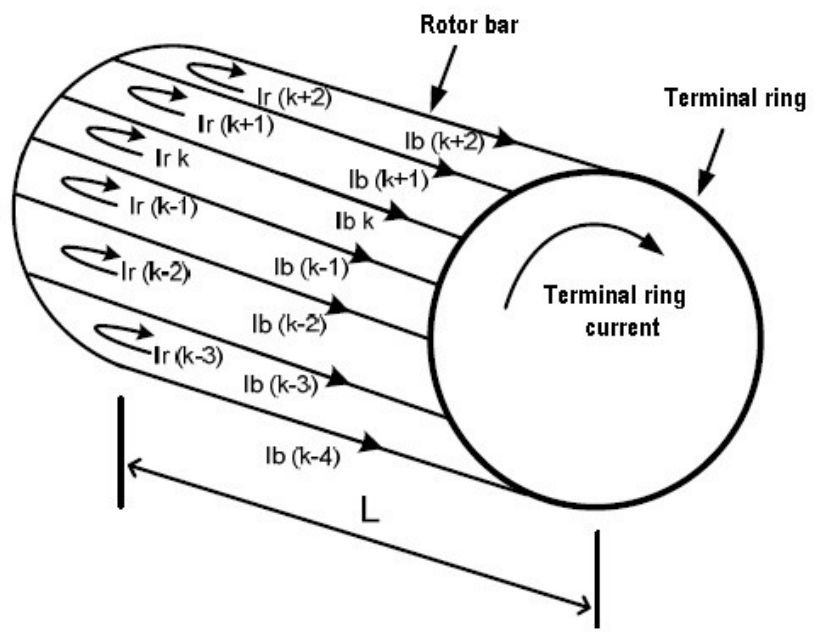

Figure 2: The current distribution in a rotor.

author [7] explains that the effect of a broken bar can be decomposed by the superposition of the two configurations. The configuration of a machine in perfect condition superimposed onto a machine with a current source of the same amplitude flowing through a broken bar, but with opposite direction, results in zero current through the bar in question. Figure 2 shows the current distribution in a rotor.

If there is only a forward rotating field at a slip frequency relative to the rotor, the cage winding is symmetrical. Where rotor asymmetry occurs, then there will be a resultant backward rotating field at a slip frequency relative to the forward rotating rotor. As a result, relative to the stationary stator winding, this backward rotating field at a slip frequency relative to the rotor induces a voltage and current in the stator winding at a frequency given by eqn. (1).

$$
f_{b b}=(1-2 s) f_{0} \mathrm{~Hz}
$$

This is referred to as a twice-slip-frequency sideband due to broken rotor bars, where $s$ is the motor slip and $f_{0}$ is the frequency of the power grid to which the motor is connected. Therefore, there is a cyclic variation in the stator current that causes a torque pulsation at the twice-slip-frequency $\left(2 s f_{0}\right)$ and a corresponding speed oscillation, which is a function of the drive inertia. This speed oscillation can reduce the magnitude of the $((1+2 s) f 0)$ sideband, but an upper sideband current component at $((1-2 s) f 0)$ is induced in the stator winding due to the rotor oscillation. This upper sideband is also enhanced by the third harmonic of the flux. Broken rotor bars, therefore, result in current components being induced in the stator winding at frequencies given by eqn. (2).

$$
f_{b b}=(1 \pm 2 s) f_{0} \mathrm{~Hz}
$$

From eqns. 1 and 2, we have a method that is relatively dependent on slip (s), which must be accurately determined to prevent false interpretations. Variations in the load are also undesirable, as explained by Henao et al. [4], which can introduce inaccuracies in the determination of the lateral frequencies. In high-efficiency motors with very low slip, this method can also present difficulties since the lateral frequencies would be very close to the fundamental $\left(f_{0}\right)$ value, which can make it difficult to detect faults in their initial stages [17].

Although widely used and accepted as a standard method, the spectral analysis approach involves challenges that have yet to be completely resolved and continues to yield inconsistent results with respect to the detection of broken half bars, non-adjacent broken bars, rotors with ventilation ducts, and false diagnoses in motors with low slip and variations in load, among others $[18,19]$.

\section{Motor Vibration Signature Analysis}

In a motor with broken bars, the current in the failed bar will be less than that in the adjacent bars, so the failed bar will contribute less torque when it passes the poles of the stator winding, thereby creating a vibration [20]. Predictive maintenance by vibrational spectrum analysis is based on the assumption that the frequency at which vibrations occur indicates which part of the machine is deteriorating [20,21].

The induction motor in a failure condition produces vibration components, which are related to the frequency source and speed of rotation. These vibrations are due to induced electromagnetic forces. Ruptured bars generate an asymmetry condition that produces a counter rotating field (at slip frequency) relative to the rotor. This field rotation interacts with the stator field to produce torque and a velocity oscillation with a frequency of $2 s f$. The oscillation velocity with the frequency $2 s f$ modulates the rotation frequency as two side bands appear around the rotation frequency fm in the vibration spectrum. These components increase in amplitude as the imbalance in the rotor circuit increases. Equation 3 describes the frequency of broken bars in an induction motor.

$f_{b b v}=\left(f_{m} \pm 2 f_{0} s\right) \mathrm{Hz}$

Where:

$f_{m}:$ Rotation frequency.

$f_{o}$ : Frequency of the power grid.

$s$ : Slip frequency.

In an induction motor with $p$ poles, the rotation frequency is slightly lower than $\frac{2 f_{0}}{p}$. By looking at the spectrum of the vibration signal, we can determine the exact mechanical frequency $f_{m}$ and its harmonics. The resolution of the frequency $\Delta f$ in a spectrum calculated by the fast Fourier transform (FFT) is reciprocal at sampling time $\mathrm{T}$. This resolution is constant across the spectrum. Thus, it is preferable to consider higher-order speed harmonics to more precisely determine slip. The harmonic of $f_{m}$ is near to and on the left side of $2 f_{0}$ in the in the vibration spectrum, and the exact slip can be given by the following [22]:

$$
\mathrm{s}=\frac{\left(2 \cdot f_{0}-p \cdot f_{m}\right)}{2 \cdot f_{0}}
$$


Citation: da Gama RS, Silva CCJ, Nascimento CEF, da Silva AM, da Costa C (2017) Analysis of Combined Motor Current Signature and Vibration-Monitoring Techniques in the Study of Broken Bars in Three-Phase High-Performance Induction Motors. J Electr Electron Syst 6: 235. doi: 10.4172/23320796.1000235

\section{Methodology}

In the experimental setup, we used a three-phase induction motor with a squirrel-cage rotor, manufactured by WEG Industries, with a power of $0.5 \mathrm{cv}, 230 / 380 \mathrm{~V}, 1750 \mathrm{rpm}$, and four poles. We acquired the stator current using a current sensor, with a 30-A AC/DC range, a transformer ratio of $100 \mathrm{mV} / \mathrm{A}$, and a frequency range of $0-20 \mathrm{kHz}$. We used an integrated electronics piezoelectric (IEPE), three-axis, $10-\mathrm{mV} /$ g accelerometer with an integrated amplification circuit to generate the mechanical vibration of the induction motor.

To record the vibration and current signals, we used a National Instruments USB 6009 data acquisition device, with a USB communication interface, a 14-bit differential and 13-bit single-ended analog/digital converter, and a sampling rate of $48 \mathrm{kS} / \mathrm{s}$. Figure 3 shows the experimental setup we used in the practical experiments. Figure 4 shows photographs of the rotor rupture bars we used in testing, with Figure $4 \mathrm{a}$ showing a healthy rotor, Figure $4 \mathrm{~b}$ a rotor with one broken bar, Figure $4 \mathrm{c}$ a rotor with two broken bars, and Figure $4 \mathrm{~d}$ a rotor with three broken bars.

\section{Results}

\section{Data acquisition algorithms}

In frequency domain analysis, we examine the signal (current and

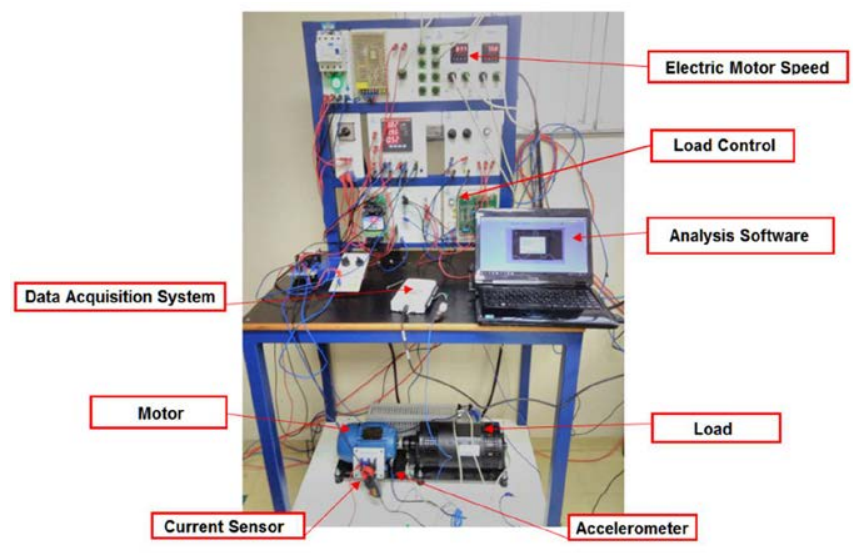

Figure 3: View of experimental setup.
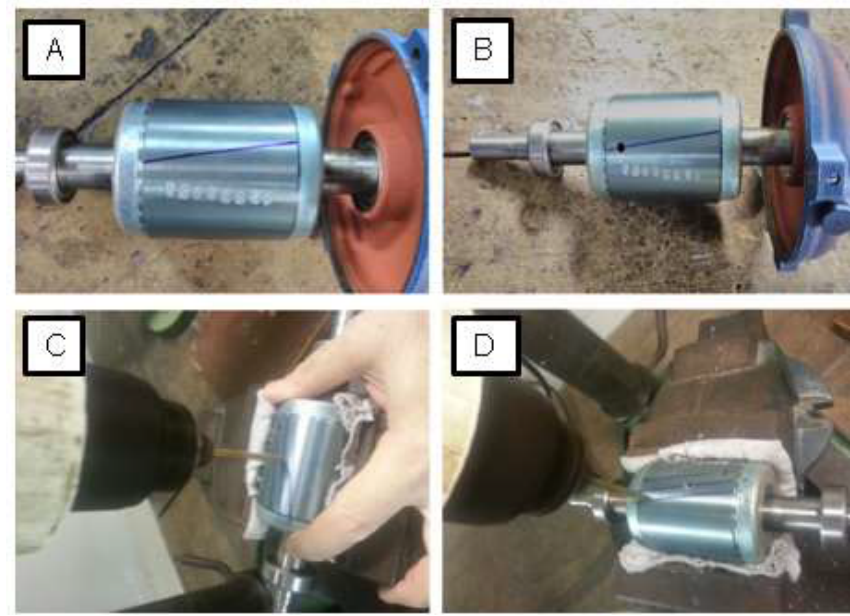

Figure 4: Rotors: a) healthy; b) one broken bar; c) two broken bars, and d) three broken bars.

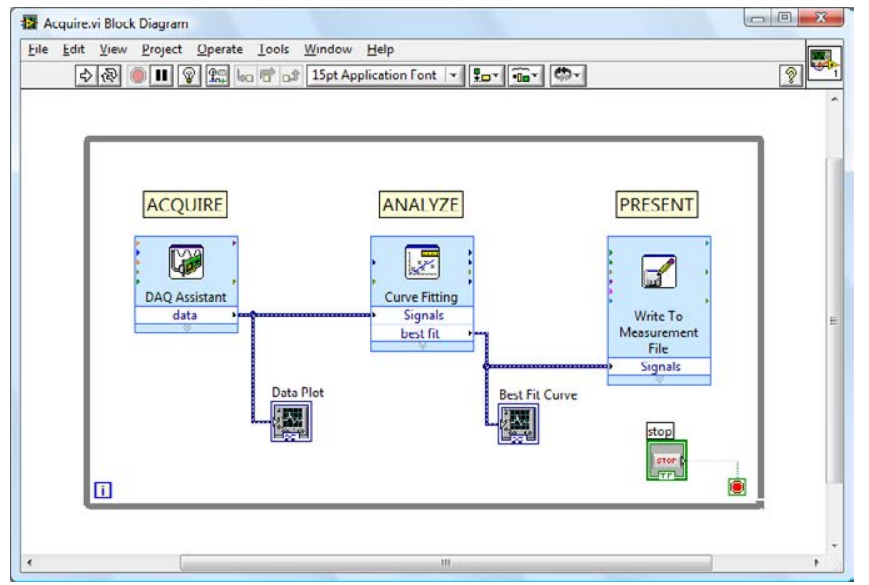

Figure 5: Block diagram of the data acquisition algorithm.

vibration) and separate the signal energy into various frequency bands. We used this frequency domain or spectral analysis of the vibration signal or current to identify failures in the induction motor. The advent of FFT computational techniques have facilitated and enhanced the efficiency of spectral analysis. In the analysis and diagnosis of faults, the bands of components with high and low frequencies in the vibration spectrum and current are of interest. We implemented our data acquisition algorithm in the software LabVIEW and Figure 5 shows a block diagram of our proposed algorithm.

\section{Stator current spectrum}

To verify the efficiency of the feature extraction method, we conducted several tests under different loads in healthy rotors and in faulty rotors with broken bars. In each case, we transformed the stator current into the frequency domain for MCSA.

Figure 6 shows the stator current spectrum for a healthy motor at $95 \%$ of the rated load and a motor speed of $1,738 \mathrm{rpm}$. The amplitude of the left broken-bar frequency component is $55 \mathrm{~dB}$ lower than that of the grid frequency $(60 \mathrm{~Hz})$, and that of the right broken-bar frequency component is $60 \mathrm{~dB}$ lower.

Figure 7 shows the stator current spectrum for one broken bar at $95 \%$ of the rated load and a motor speed of $1745 \mathrm{rpm}$. We analyzed and extracted the fault frequency components (left broken-bar frequency) at $57,50 \mathrm{~Hz}$ and the right broken-bar frequency at $62,50 \mathrm{~Hz}$. The amplitude is $40 \mathrm{~dB}$ lower than that of the grid frequency and the amplitude frequency of the left broken-bar component is $55 \mathrm{~dB}$ lower.

Figure 8 shows the stator current spectrum for two broken bars at $85 \%$ of the rated load and a motor speed of $1746 \mathrm{rpm}$. We analyzed and extracted the fault frequency components of the left broken-bar frequency at $57,50 \mathrm{~Hz}$ and the right broken-bar frequency at $62,50 \mathrm{~Hz}$. The amplitude is $35 \mathrm{~dB}$ lower than that of the grid frequency and the amplitude of the left broken-bar component is $40 \mathrm{~dB}$ lower.

\section{Vibration spectrum}

In the broken bar cases, there is an oscillation speed with the frequency $2 s f_{0}$, which modulates the rotation frequency, so that two lateral bands $\left(f_{m} \pm 2 s f\right)$ appear around frequency $f_{m}$. To determine the values of $f_{m}$ and $s$ more precisely, we can check the higher-order harmonics of the rotation frequency. In vibration spectra, the P-th harmonic ( $\mathrm{P}=4$ poles) 4. $f_{m}$ is near and to the left side of $2 . f_{0}$, and the slip $(s)$ can be given by Eq. 5 . 
Citation: da Gama RS, Silva CCJ, Nascimento CEF, da Silva AM, da Costa C (2017) Analysis of Combined Motor Current Signature and Vibration-Monitoring Techniques in the Study of Broken Bars in Three-Phase High-Performance Induction Motors. J Electr Electron Syst 6: 235. doi: 10.4172/23320796.1000235

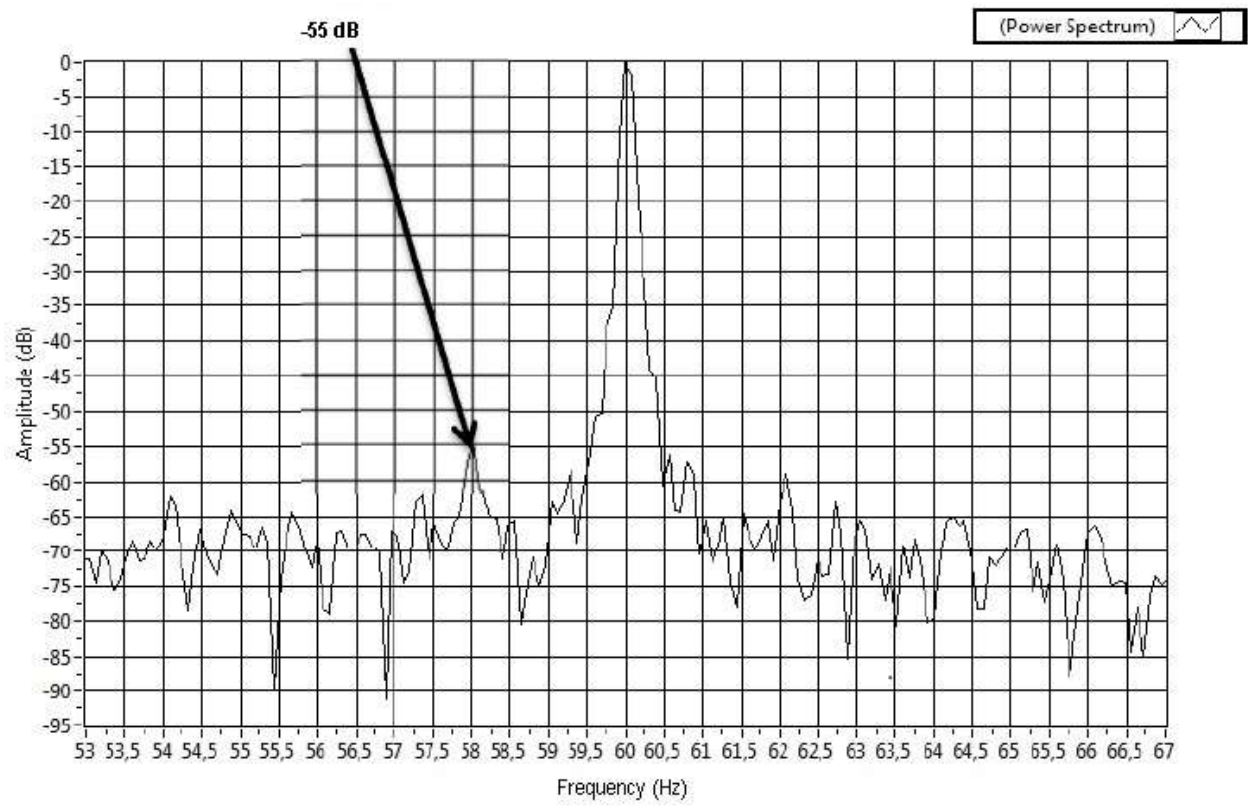

Figure 6: Current spectrum for a healthy motor.

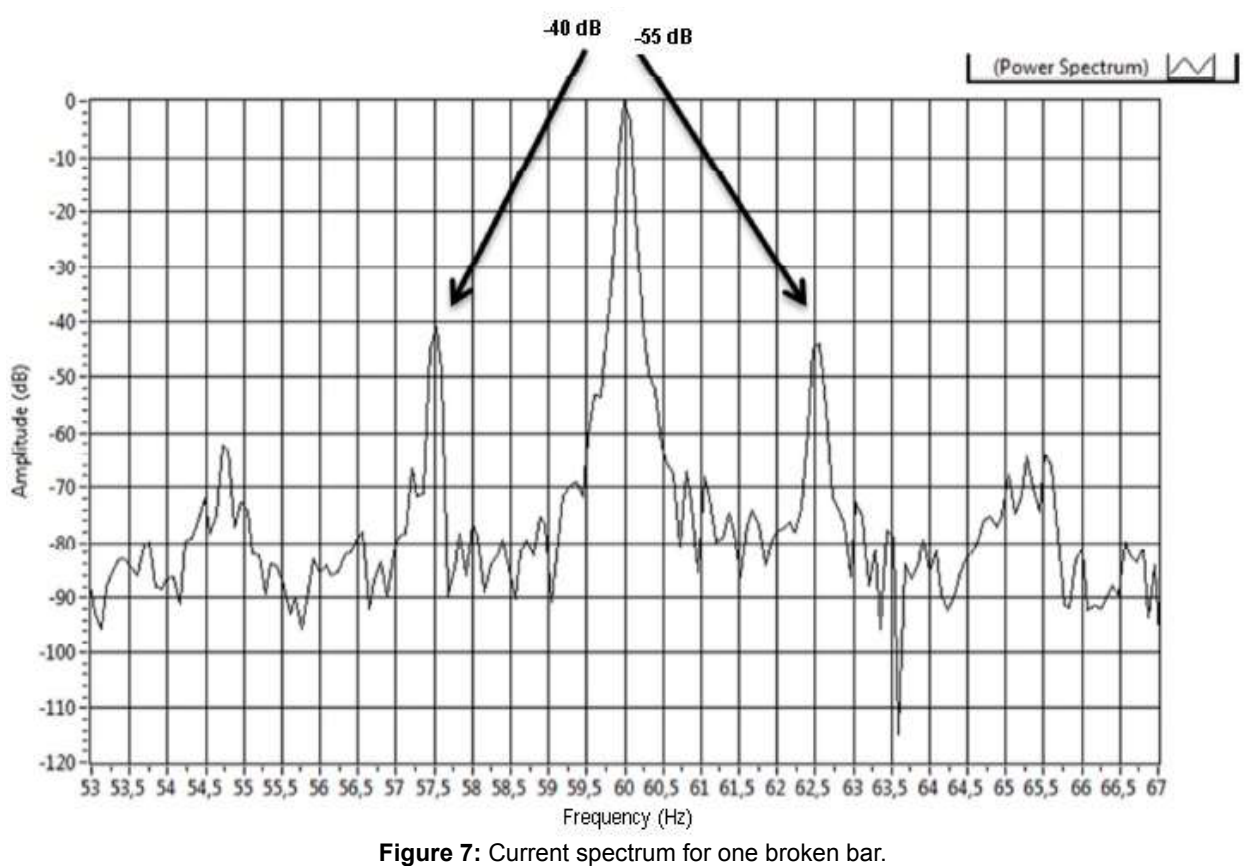

$$
\mathrm{s}=\frac{\left(2 \cdot f_{0}-4 \cdot f_{m}\right)}{2 \cdot f_{0}}
$$

Figure 9 shows our first data results using the vibration spectrum method. The slip calculated by Eq. 5 is equal to 0.0247 and the motor rotation frequencies $\left(f_{m}\right)$ are $29,26 \mathrm{~Hz}$. The harmonic frequencies $4 \times$ $f_{m}$ and $2 \times f_{0}$ are, respectively, $117.04 \mathrm{~Hz}$ and $120 \mathrm{~Hz}$. In Figure 10, the power spectrum of the two sidebands, i.e., $\left(f_{m}-2 s f_{0}\right)$ of $26,30 \mathrm{~Hz}$ and $\left(f_{m}+2 s f_{0}\right)$ of $32,94 \mathrm{~Hz}$ near $f_{m}$, are well below $-60 \mathrm{~dB}$, which indicates that there are no broken-bar faults.
Figure 11 shows the vibration spectrum for one broken bar at $90 \%$ of the rated load and motor rotation frequencies $\left(f_{m}\right)$ of $29,26 \mathrm{~Hz}$. In this figure, the power spectrum of the two sidebands $\left(f_{m}-2 s f_{0}\right)$ of 25,30 $\mathrm{Hz}$ and $\left(f_{m}+2 s f_{0}\right)$ of $32,82 \mathrm{~Hz}$ allow us to identify with some difficulty two lateral bands near $f_{m}$, thereby indicating the presence of a broken bar fault.

Figure 12 shows the vibration spectrum for two broken bars at $90 \%$ of the rated load and a motor rotation frequency $\left(f_{m}\right)$ of $29,10 \mathrm{~Hz}$. In the figure, the power spectrum of the fault frequency component sidebands $\left(f_{m} \pm 2 s f_{0}\right)$, are equal to $25,50 \mathrm{~Hz}$ and $32,70 \mathrm{~Hz}$. We can 
Citation: da Gama RS, Silva CCJ, Nascimento CEF, da Silva AM, da Costa C (2017) Analysis of Combined Motor Current Signature and Vibration-Monitoring Techniques in the Study of Broken Bars in Three-Phase High-Performance Induction Motors. J Electr Electron Syst 6: 235. doi: 10.4172/23320796.1000235

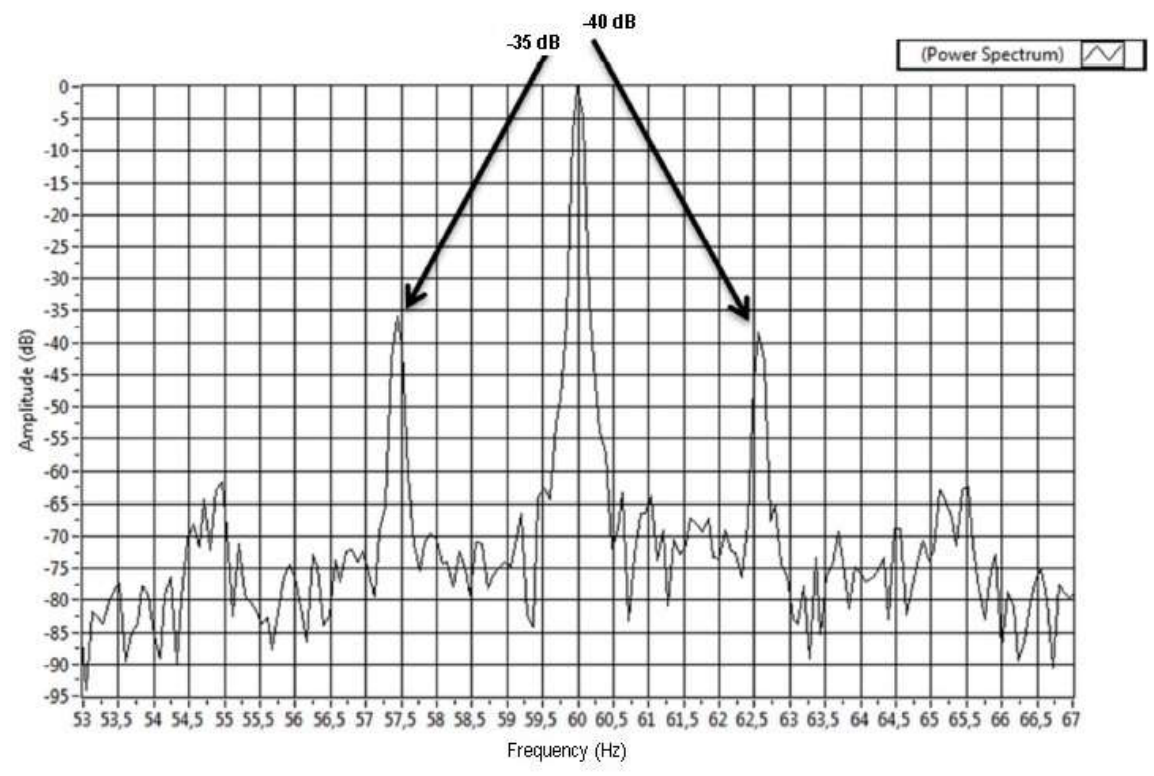

Figure 8: Current spectrum for two broken bars.

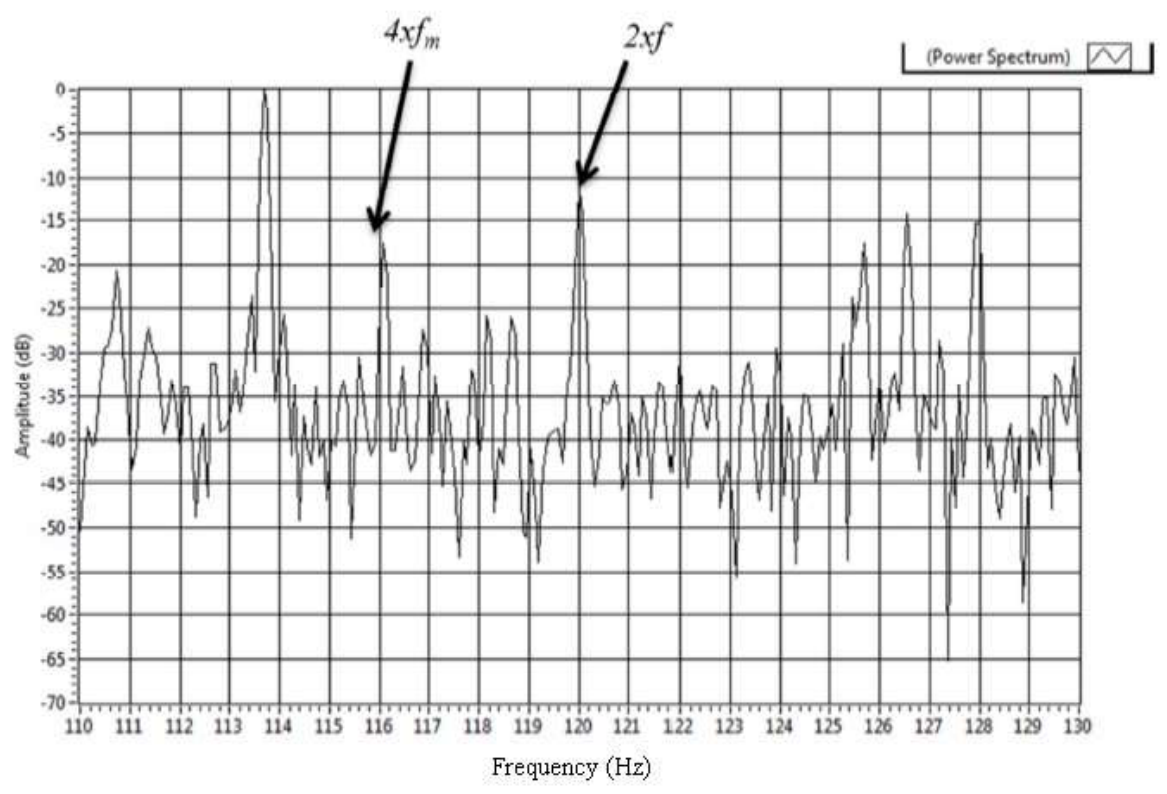

Figure 9: Vibration spectrum for slip calculation.

see an increase in the amplitude of the lateral bands $\left(f_{m} \pm 2 s f_{0}\right)$, which indicates the presence of a two broken-bar fault.

\section{Conclusion}

In this paper, we developed and tested an analysis method that combines MCSA and a vibration-monitoring technique to study broken bars in three-phase high-performance induction motors. The combined MCSA and vibration-monitoring technique can be used to monitor non-invasive sensor signals and identify broken-bar conditions in induction motors.

We presented a detection method using stator current and vibration spectra to determine the presence of broken-bar faults in induction motors.

From our analysis of these spectra, we found the detection of broken bars by signature analysis of the stator current to be more sensitive and applicable to high-performance induction motors. In the initial stages of failure, both methods presented some difficulties in detection, in that only from the second adjacent broken bars could we verify the amplitude of the fault frequency component sidebands with sufficient clarity in both spectra.

The combined method of current signature and vibration spectrum analyses can increase detection reliability since the vibration spectrum 
Citation: da Gama RS, Silva CCJ, Nascimento CEF, da Silva AM, da Costa C (2017) Analysis of Combined Motor Current Signature and Vibration-Monitoring Techniques in the Study of Broken Bars in Three-Phase High-Performance Induction Motors. J Electr Electron Syst 6: 235. doi: 10.4172/23320796.1000235

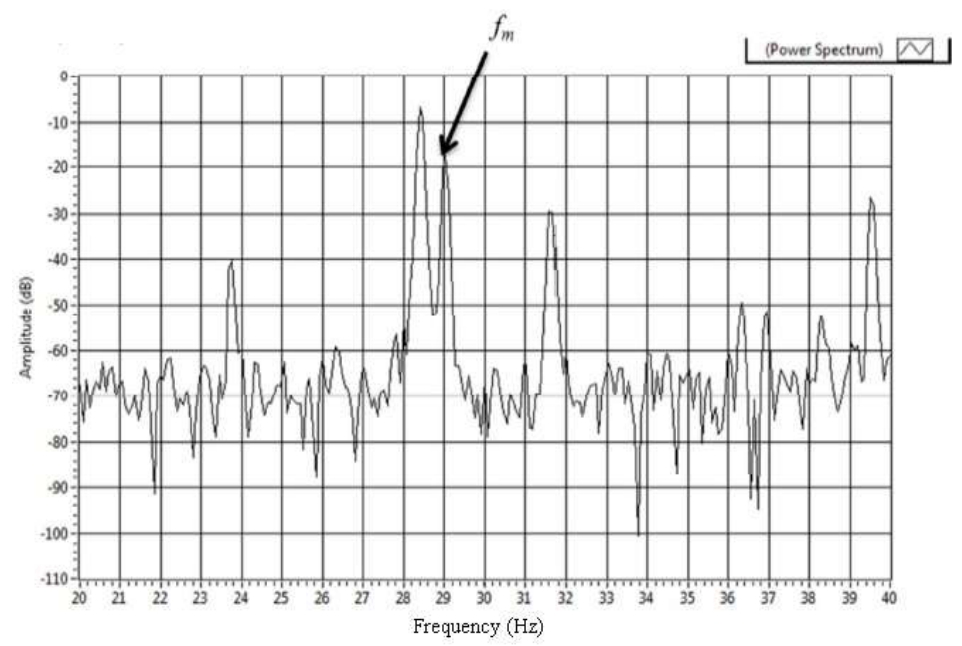

Figure 10: Vibration spectrum for the healthy motor.

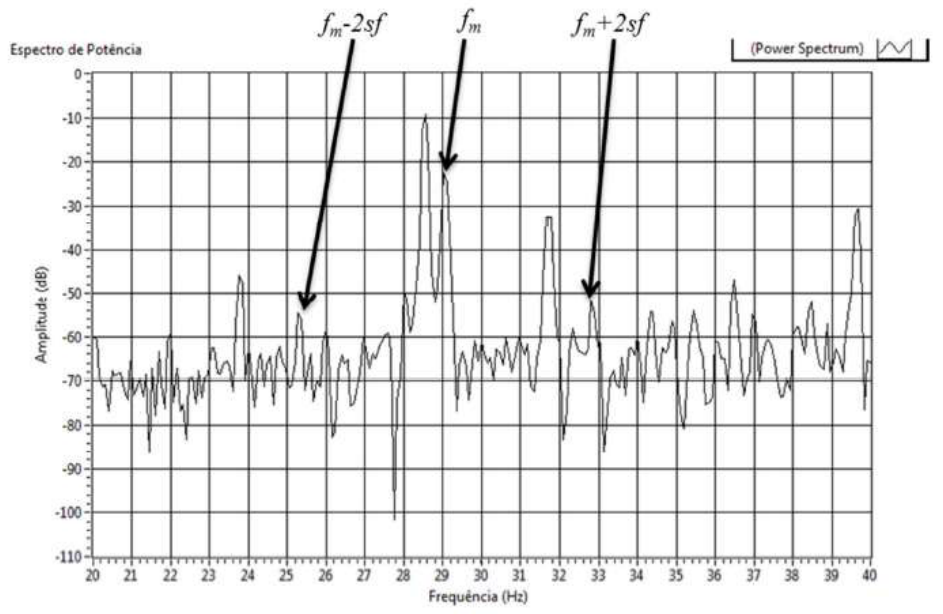

Figure 11: Vibration spectrum for one broken bar.

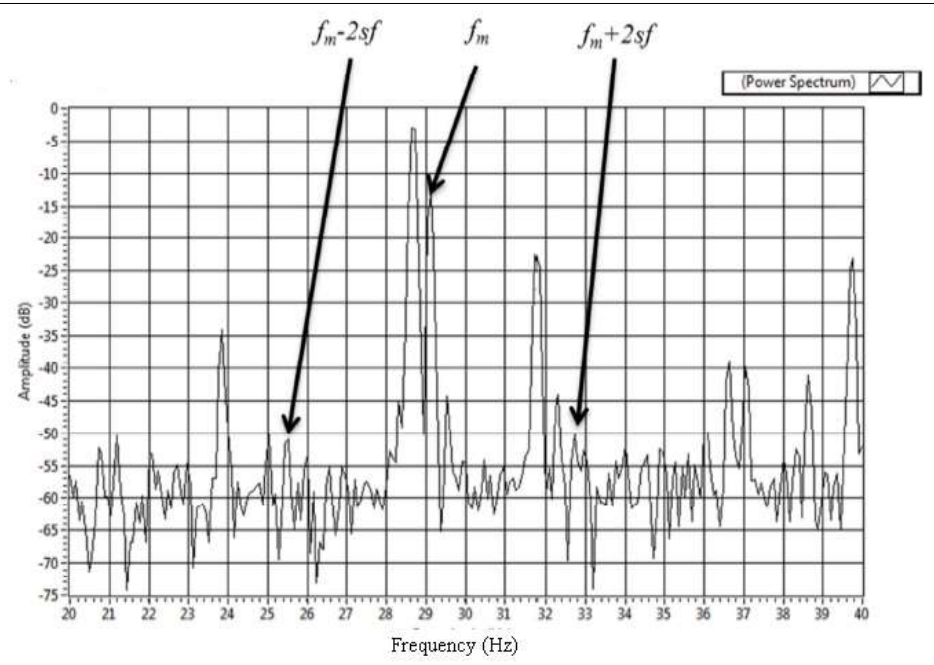

Figure 12: Vibration spectrum for two broken bars. 
Citation: da Gama RS, Silva CCJ, Nascimento CEF, da Silva AM, da Costa C (2017) Analysis of Combined Motor Current Signature and Vibration-Monitoring Techniques in the Study of Broken Bars in Three-Phase High-Performance Induction Motors. J Electr Electron Syst 6: 235. doi: 10.4172/23320796.1000235

method is less sensitive to load variations, which can cause fluctuations to be reflected in the frequency spectrum that may lead to erroneous conclusions.

\section{References}

1. Ahamed SK, Sarkar A, Mitra M, Sengupta S (2012) Detection of induction motor broken bar fault through envelops analysis using start-up current. Procedia Technology 4: 646-651.

2. Boughrara K, Takorabet N, Ibtiouen R, Touhami O, Dubas F (2015) Analytical analysis of cage rotor induction motors in healthy, defective and broken bars conditions. IEEE Transactions on Magnetics 51: 1-17.

3. Salem SB, Bacha K, Chaari A (2012) Support vector machine based decision for mechanical fault condition monitoring in induction motor using an advanced Hilbert-Park transform. ISA transactions 51: 566-572.

4. Henao H, Bruzzese C, Strangas E, Pusca R, Estima J, et al. (2014) Trends in fault diagnosis for electrical machines: A review of diagnostic techniques. IEEE Industrial Electronics Magazine 8: 31-42.

5. Naha A, Samanta AK, Routray A, Deb AK (2016) A method for detecting half-broken rotor bar in lightly loaded induction motors using current. IEEE Transactions on Instrumentation and Measurement 65: 1614-1625.

6. Siddiqui KM, Sahay K, Giri V (2015) Rotor broken bar fault detection in induction motor using transformative techniques. Journal of Electrical Engineering 15 $135-141$

7. Costa CDa, Kashiwagi M, Mathias MH (2015) Rotor failure detection of induction motors by wavelet transform and Fourier transform in non-stationary condition. Case Studies in Mechanical Systems and Signal Processing 1: 1526.

8. Pires VF, Kadivonga M, Martins J, Pires A (2013) Motor square current signature analysis for induction motor rotor diagnosis. Measurement 46: 942 948.

9. Xu B, Sun L, Xu L, Xu G (2013) Improvement of the Hilbert method via ESPRIT for detection rotor fault in induction motors at low slip. IEEE Transaction on Energy Conversion 28: 225-233.

10. Garcia-Perez A, Romero-Troncoso RDJ, Cabal-Yepez E, Osornio-Rios RA (2011) The application of high-resolution spectral analysis for identifying multiple combined faults in induction motors. IEEE Transactions on Industrial 58: $2002-2010$
11. Kim YH, Youn YW, Hwang DH, Sun JH, Kang DS (2013) High-resolution parameter estimation method to identify broken rotor bar faults in induction motors. IEEE Transactions on Industrial Electronics 60: 4103-4117.

12. Bouchikhi EHE, Choqueuse V, Benbouzid MEH (2015) Induction machine faults detection using stator current parametric spectral estimation. Mechanical Systems and Signal Processing 52: 447-464.

13. Sapena-Bano A, Pineda-Sanchez M, Puche-Panadero R, Perez-Cruz J, RogerFolch J, et al. (2015) Harmonic order tracking analysis: a novel method for fault diagnosis in induction machines. IEEE Transactions on Energy Conversion 30: 833-841.

14. Antonino-Daviu J, Gyftakis K, Cardoso AM (2016) A reliable indicator to detect non-adjacent broken rotor bars severity in induction motors. International Conference on Electrical Machines (ICEM).

15. Wang J, Gao RX, Yan R (2011) Broken-rotor-bar diagnosis for induction motors. Journal of Physics: Conference Series 305: 1-10.

16. Bouleux G (2013) Oblique projection pre-processing and TLS application for diagnosing rotor bar defects by improving power spectrum estimation. Mechanical Systems and Signal Processing 41: 301-312.

17. Kaikaa MY, Hadjami M (2014) Effects of the simultaneous presence of static eccentric and broken rotor bars on the stator current of induction machine. IEEE Transactions Ind. Electron 61: 2452-2463.

18. Cruz MA (2012) An active reactive power method for the diagnosis of roto faults in three-phase induction motors operating under time-varying load conditions. IEEE Transactions on Energy Conversion 27: 71-84.

19. Climente-Alarcon V, Antonio-Daviu JA, Strangas EG, Riera-Guasp M (2015) Rotor-bar breakage mechanism and prognosis in induction motor. IEEE Transactions Ind Electron 62: 1016-1020.

20. Kim DJ, Kim HJ, Hong JP, Park CJ (2014) Estimation of acoustic noise and vibration in an induction machine considering rotor eccentricity. IEEE Transactions on Magnetics 50: 857-860.

21. Seshadrinath J, Singh B, Panigrahi BK (2014) Investigation of vibration signature for multiple fault diagnosis in variable frequency drives using complex wavelets. IEEE Trans Power Electron 29: 936-945

22. Delgado-Arredondo PA, Morinigo-Sotelo D, Osornio-Rios RA, Avina-Cervantes JG, Rostro-Gonzales H, et al. (2017) Methodology for fault detection in induction motors via sound and vibration signals. Mechanical Systems and Signal Processing 83: 568-589. 